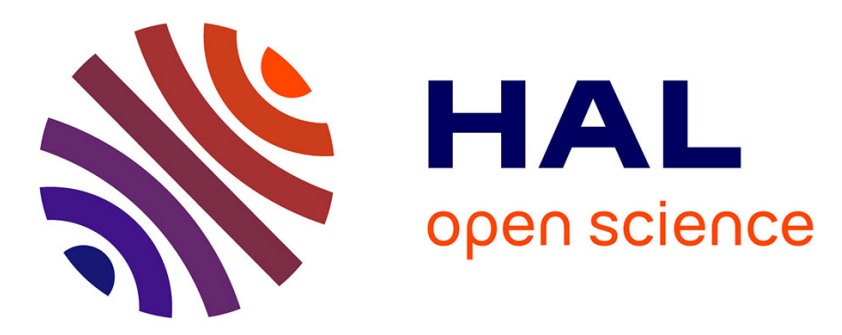

\title{
Investigating Notifications and Awareness for Multi-user Multi-touch Tabletop Displays
}

Shuo Niu, D. Scott Mccrickard, Steve Harrison

\section{To cite this version:}

Shuo Niu, D. Scott Mccrickard, Steve Harrison. Investigating Notifications and Awareness for Multiuser Multi-touch Tabletop Displays. 16th IFIP Conference on Human-Computer Interaction (INTERACT), Sep 2017, Bombay, India. pp.223-244, 10.1007/978-3-319-67687-6_15 . hal-01717197

\section{HAL Id: hal-01717197 \\ https://hal.inria.fr/hal-01717197}

Submitted on 26 Feb 2018

HAL is a multi-disciplinary open access archive for the deposit and dissemination of scientific research documents, whether they are published or not. The documents may come from teaching and research institutions in France or abroad, or from public or private research centers.
L'archive ouverte pluridisciplinaire HAL, est destinée au dépôt et à la diffusion de documents scientifiques de niveau recherche, publiés ou non, émanant des établissements d'enseignement et de recherche français ou étrangers, des laboratoires publics ou privés. 


\title{
Investigating Notifications and Awareness for Multi-user Multi-touch Tabletop Displays
}

\author{
Shuo Niu, D. Scott McCrickard, and Steve Harrison \\ Computer Science Department, Virginia Tech \\ 2202 Kraft Drive, Blacksburg, VA 24060, U.S.A. \\ \{shuoniu, mccricks, srh\}@vt.edu
}

\begin{abstract}
Notifications seek to guide people's attention toward timely, relevant, and important tasks and interactions. This work considers situations in which multiple people are sharing a single large display, with collaborative notifications targeted at increasing team awareness of the joint goals, activities, and interactions. Notifications in recent studies show promise in enhancing awareness of the actions of co-located collaborators, but lacking is critical knowledge to guide the evaluation of the benefits and costs of collaborative activities. This paper presents a framework for notifications in a multi-user multitouch context. The framework is explored for a card-sorting task performed by two people (a participant and a scripted confederate) on a shared tabletop display. Notifications highlight actions performed by each participant to understand changes in social, action, and activity awareness. Our study investigates individual work, social norms and team performance as three co-located factors that are affected by incorporating notifications.
\end{abstract}

Keywords. Awareness; notification; multi-user multi-touch; social; action; activity.

\section{Introduction}

Recent advances in multi-user multi-touch (MUMT) displays enable support for rich and complex simultaneous co-located collaboration. Multi-touch tabletop displays and wall-mounted displays provide collaborative spaces where people simultaneously interact with the digital content while being able to see and talk to each other, but use of these large displays introduce issues regarding how to support multi-person interaction. Distinguishing characteristics of tabletops, compared to other shared large displays, relates to the increased physical size and the support for multiple simultaneous touches. These differences allow users to establish their own personal spaces within the display and work on complex multi-handed tasks, with added potential to ignore the activities of others-necessitating awareness support such as notifications.

Prior studies have explored how visual designs and notifications influence awareness in collaboration [18, 20, 22]. Shared display notifications seek to address awareness problems, but studies suggest that incorporating notifications comes with attentional cost. Understanding and balancing such tradeoffs center the design and evalua- 
tion of notification techniques. Carroll et al. aggregated knowledge from prior studies on collaborative awareness (e.g. [12, 16, 22]), concluding that collaborators' social, action, and activity awareness must be balanced by notifications [4]. This paper considers those three types of awareness, expanding their definitions to encompass the unique nature of MUMTs - highlighting the importance of awareness of shared activities in MUMT use.

We leverage the model identified by Carroll et al., expanding it into a framework that describes the effect of notification in tabletop-based co-located context. Individual work, social norms, and team performance are three collaboration factors in the framework, for which notifications have significant influence in social, action, and activity awareness. The framework provides an understanding of the effects of notifications-both benefits and costs - in influencing collaborative awareness over the MUMT display. The research outcome provides knowledge for MUMT designers to better use and evaluate notifications in supporting co-located awareness.

The framework is examined in a laboratory study with 61 participants. The study focused on a collaborative card-sorting task, exploring whether notifications that show collaborator activities affect awareness. The results consider two metrics for each of social, action, and activity awareness. The study demonstrates an increased awareness of the actions of others when using notifications, highlighting differences in social norm, task performance, and individual work. The results suggest a research agenda that encourages further investigation toward understanding not only how notifications affect social, action, and activity awareness, but also how notifications can be designed and used to encourage sharing and enhance communication.

\section{Related Work}

Prior work has highlighted the importance of awareness in collaboration and the value of notifications in helping to achieve awareness. This section examines arguments for why awareness is important, provides an overview of notification research, and describes how prior notification work has relevance to the emerging MUMT domain.

Situation awareness suggests that individual awareness of specific elements, team awareness of shared elements, and communication to share awareness information are critical to teamwork $[13,36,53]$. Understanding of personal workspace helps determine how team members make decisions and takes actions [12]. A high degree of team shared awareness implies collaborators' understanding of the shared elements, which is core to common ground [7, 41, 53]. Protocols to develop common ground is a part of social conventions in exchanging awareness information $[4,35,50]$. As such, maintaining awareness of others' actions has long been a topic of interest, including in Gutwin's framework for exploring workspace awareness [22] and Fussell's exploration of how visual cues help the conversational grounding and reduce the efforts to maintain situation awareness $[18,20]$.

Among the many techniques for awareness, notifications have been widely used to deliver information and achieve awareness $[3,4,8,46]$. When working in a shared interaction space, people allocate attention to incoming notifications to maintain 
awareness of collaborators' presence, speech, and activities [22, 23]. The design of notifications for collaborative systems considers tradeoffs between utility benefits and attention costs $[4,6,38]$. Studies show that introducing notifications in groupware may heighten awareness of group work, but restrict individual progress $[4,11]$. However, with the emergence of novel collaboration technologies like MUMTs, notification and awareness remain underexplored.

Existing MUMT research introduced (though did not always explicitly discuss) ways to support awareness in teamwork [37, 42, 56, 60]. Affordances of large interaction spaces, face-to-face communication, and simultaneously accessible multitouch not only support collaboration modalities [31,59], but also provide ways to observe others' activities [31, 37, 55, 61]. As one would expect, efforts to make actions on MUMT displays visible to others lead to new awareness issues. For example, WeSearch and Cambiera integrated interactive visualization widgets to inform collaborators about searches and enhance the awareness of activities, though investigations of both tools suggest that awareness-enhancing widgets lack sufficient communicative benefits to support close collaboration [30, 42]. Pogat is an affective virtual agent that resides at the corner of MUMT tabletops to support affective awareness, resulting in extroverted personal feelings communicated by the tool that sometimes makes people uncomfortable [21]. SIDES uses co-dependent tangible tools to achieve action and activity awareness in a tabletop game, sometimes resulting in idea conflicts when children use the tool one at a time. [14]. Interactive maps OrMis and Canyon use secondary views to support mutual awareness in collaborative exploration, with study results suggesting people often work in turn-taking instead of simultaneously [3, 28]. Navi Badgeboard and Navi Surface use digital badges to increase the awareness of personal achievements and group activities, with a study implying that badges make the student hesitate to participate in collaboration without others' confirmation [5].

Problems with awareness-enhancing techniques in MUMTs are pertinent to individual and team awareness, particularly the effectiveness of communication. Utility and collaboration breakdowns stemming from notifications suggest a need to evaluate how MUMT affordances influence tradeoffs identified in traditional collaboration research. Carroll et al. drew from situation awareness, common ground and workspace awareness in suggesting that social awareness, action awareness, and activity awareness are core in notification design [4]. The model provides awareness breakdowns and suggests practical design strategies for notification systems. This work scopes how notifications may affect group activities, but the large interaction space [52], face-to-face communication [61], dynamic work styles [59], and multi-touch interactions afforded by MUMT displays introduce other factors unique to the MUMT-supported collaboration. The new contextual elements influence how collaborators perceive and react to notifications $[12,57]$.

Designing notifications for MUMTs needs a conceptual model to outline the benefits of raising collaborative awareness and the costs of interrupting individual tasks. Our research considers the contextual change in collaborative MUMTs, seeking to expand previous understanding of notifications in traditional computer-supported collaboration with the unique aspects of notifications on tabletop displays. 


\section{$3 \quad$ MUMT Displays and Collaborative Awareness}

Staying aware of others' activities is a secondary but valuable part of co-located collaboration $[4,11]$. When collaborating using a MUMT display, people monitor others' activities through multiple communication channels: listening to what others are saying, observing others' body gestures, seeing others' touch actions, and revisiting changes. Awareness on tabletop applications can be augmented with notifications showing others' activity, e.g., visual effects highlighting digital items. Notifications in the co-located workspace inform collaborators of prior group activities, but may influence individual activities and the manner in which collaborators participate group work. To connect prior work on notification design with practical application of MUMT notifications, we examine the use of co-located notifications with Carroll's awareness model. Carroll's model incorporates 3 high-level awareness types with a knowledge structure about notifications in collaborative systems. Action, social and activity awareness are refined from prior research on collaborative awareness, including situation awareness [12], workspace awareness [22, 24] and visual-based grounding process [16]. The model is rooted in practical use of collaborative notifications and clarifies the awareness categories that must be supported through notifications.

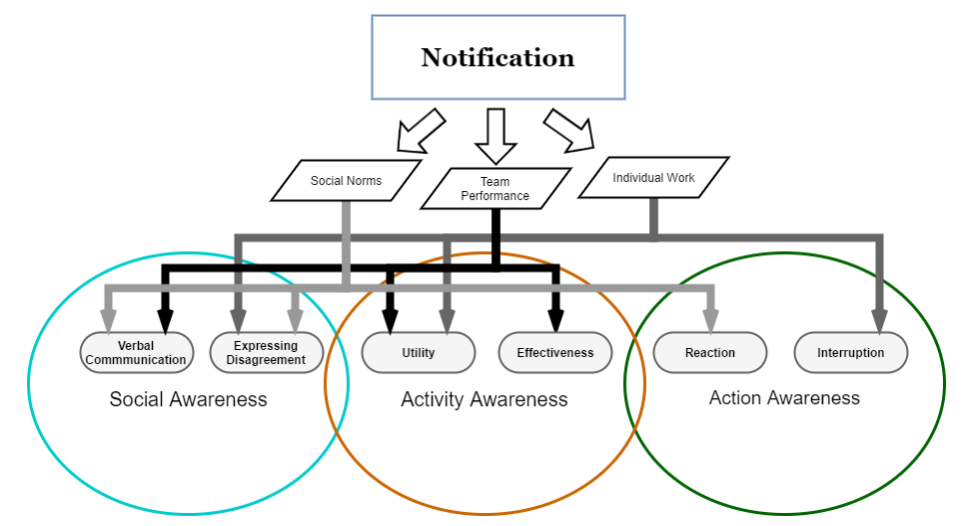

Fig. 1. Framework showing how notifications influence different types of awareness.

Action Awareness. Action awareness refers to the understanding of the ongoing actions carried out by collaborators. In collaborative applications, people know what objects are shared with others and who is modifying them through indicators on the screen. As a part of workspace awareness, these indicators reflect immediate and synchronous actions to the shared artifacts (e.g. what questions addressed by workspace awareness information), which influences one's own decision about the next action [12, 22]. MUMT displays provide large interaction space, enabling collaborators to work at different screen position while being able to see what others are doing. The division of screen space, referred as territoriality [54], reflects the space need for both individual and collaborative tasks. However, when observing actions in another's territory, awareness might be restricted by the form factors of the display [9, 33]. 
MUMT affordances influence factors such as reaction to the other's activity and interruptions to individual work. Direct touch affects how people react to others' actions, since responding in face-to-face collaboration is preferred to be timely, and body cues may attract others' attention. Due to large screen size, reacting to a notification and moving attentional focus requires cognitive effort. People usually defer or even completely leave their own ongoing work when they react to the notified item on the other side of the display [47]. The immediate reaction is a source of breakdowns and may cause interruptions to individual workflow.

Social Awareness. In CSCW, social awareness refers to knowledge of the presence of collaborators. Particularly in remote collaboration, people want to know about collaborators: anyone is available, who is around, who is doing the actions, and other social factors not visible to collaborators [22, 40]. These questions form people's understanding to the presence and identity of other collaborators, as well as the authorship of the actions [22]. Collaborators use language and other visual medium to maintain social awareness, which is a part social interactions for building common ground $[7,19,20]$. When collaborating using a tabletop display, however, issues of existence and engagement is different. The large interaction space affects social interaction. For example, recent study suggests that communication reduces with larger size of the shared display [61]. The introduction of MUMT technology for co-located presence makes mood-related factors such as verbal communication and expressing disagreement more important [31, 48]. In addition, social presence in a co-located context also encourages collaborators to react to each other or their digital representations (e.g. notifications) [49]. For example, responding to another's action with utterances or body cues shows awareness of other's thoughts and activities [26]. Giving an appropriate response can not only move forward the task, but also increase connectedness and build a closer working relationship. Asking about actions verbally helps capture others' purpose and plan in the collaborative task [22]. Awareness of the social context also influence the exchanging and merging of the individual awareness to develop common ground [53]. In co-located interaction with tabletops, the awareness to the other's social presence might influence people's willingness to consider different possibilities and express disagreements.

Activity Awareness. Activity awareness is the perception of collaborators' plans and motivations [4]. Activity awareness includes not only many aspects of social and action awareness through an understanding of the overall situation, but also a deeper understanding of the current and past workspace information throughout various collaborative events [22]. Activity awareness established from communication and shared views highly influence the effectiveness of collaboration [19, 20]. Higher activity awareness may simplify conversation and coordinate actions in the workspace $[20,22]$. Establishing effective activity awareness on MUMTs is challenging. Collaborators are usually involved with others' work in different coupling styles-working separately in a loosely-coupled style or intensively with a close-coupled style [58]. Closer relationships improve collaboration outcomes, but people still need to work independently $[30,58]$. Collaborators might be working in parallel during the collaboration, though the size and multi-touch capabilities can result in people not under- 
standing others' activities. But others' activities in the collaborative task can affect individual work [29]. Awareness of the team situation influences the utility of the digital artifacts and the effectiveness of group work. Although most MUMTs are simultaneously accessible to all collaborators, people need to monitor other's actions on the shared items to decide the appropriateness one's own actions [53]. This understanding, which can be obtained from reading notifications, affects the utility of personal items. Failing to understand others' activities might lead collaborators to perform spurious work. Notifications indicating other's activities have promise in avoiding these problems and boost collaboration, but only if appropriately used.

\section{$4 \quad$ Notification and Awareness}

A notification is a way to "deliver the current, important information to users in an efficient and effective manner, without causing unwanted distraction to ongoing tasks" [40]. Notifications can heighten awareness of collaborators' activities, though they also introduce costs. Collaborative notification in our research has two characteristics: it presents an immediate alert after the partner makes an important change, and it provides enduring information about past activities. Previous knowledge of notification design and the unique form factors of MUMTs reveals three areas for which notifications affect awareness - individual work, social norms, and team performancethat help clarify the manner in which notifications affect collaborative awareness.

Individual Work. Individual situation awareness is the understanding to the status of the collaborative environment and leads to decision making and action execution [12]. Acting on items used by others, expressing diverse ideas, and pausing individual work to give responses are consequences of awareness to one's own responsibilities. During individual work, the degree for which each collaborator understands the impact of other's activities modifies the individual utility of the shared items. In MUMT collaboration, utility is embodied by which and how touch items are visited. An incoming notification distracts a user's attention from the current focus area to the notification. Given the large interaction space of MUMTs, moving attentive focus might interrupt individual actions, causing breakdowns in workflow. Disagreement may also be limited when notified that a different decision has already been made, for better or worse. Notifications in the face-to-face context heightening awareness of other's activities might enhance mutual understanding, but may also discourage individual thoughts.

Social Norms reflect conventions that affect the grounding process in which people communicate and exchange awareness information [7, 17, 20]. With MUMT notifications, collaborators obtain a way to acknowledge and respond to others' activities in the co-located space. Notifications serve as an embodiment of others' presence and activities. In addition to body cues, people can also acknowledge and react to others through interaction with notifications. But higher awareness of social presence may reduce verbal conversations. Notifications manifesting collaborators' past decisions may affect people's willingness to make changes, especially for items changed by 
others. These influences imply that notifications impact awareness of co-located social context and alter the social norms that guide co-located group work.

Team Performance. Notifications showing other's activities may potentially influence the performance of the collaborative task. Team performance in this study focus on how team situation awareness influence the overall utility and effectiveness of collaborative interaction. Notifications indicating the key changes assist the understanding of other's behavior. With higher awareness of other's actions and activities, people may simplify the face-to-face conversation to make the interaction more efficient $[22,34]$. Notifications are also a part of the information upon which people make decisions on the next-up activities. Better understanding of others' activities helps people monitor the progress of the collaborative task, thereby increasing potential effectiveness of the collaboration. Notifications indicating the status of the digital objects help people decide which one to use and influence overall utility of the digital items on the MUMT display.

Framework of Notification and Co-located Awareness. Figure 1 summarizes how notifications impact different types of awareness, with individual work, team performance, and social norms as factors affected by notifications. The manner in which notifications influence social, action, and activity awareness comes from connections among factors and aspects in MUMT collaboration for each type of awareness. To better understand the role of notifications in co-located collaboration, a laboratory study is conducted with a collaborative card-sorting task on a MUMT display.

\section{$5 \quad$ Supporting Card Sorting}

Card sorting is a common method for organizing information in sense-making activities [27]. In this collaborative information organization activity, people explore a set of cards and sort them into categories. Each card contains an item, and cards in the same category share characteristics. In a card-sorting task, collaborators communicate to share thoughts, manipulate cards to explore the card content, and observe the card status to track the overall task progress. Analogous exploration and decision-making activities on MUMTs can be found in other examples [9, 25, 30, 43].

A card-sorting system is developed with Windows Presentation Foundation on a MUMT display. For our study, the system uses two identical sets of digital cards on two sides of the tabletop. Cards consist of text and pictures representing items to be sorted. Any card can be moved, rotated and zoomed with common multi-finger touch operations [60] by multiple people simultaneously. The system was designed with the guidelines proposed by Morris et al. [44] and Scott et al. [54, 55], replicating controls in each collaborator's personal space. Similar interface layouts can be seen in many other studies $[29,51,61]$. The color-coded category bins are in the center of the table. Users can drag and drop a card onto a bin to categorize it. The card background turns the same color as the bin when sorted. The notification used in the tool consists of an animation and a background color change (Figure 2). When one user sorts a card into the bin, the card with the same content on his partner's side will shake for one second 
and then its background changes color. The animation informs the collaborator of an change, with the color indicating card category. Animated notifications have been shown to better attract user's attention compared to other generic notifications [2], which should help raise awareness when using large tabletop displays.

\section{Indicators of Awareness}

There is no complete collection of metrics that fully reflect the different types of awareness, but we sought to identify a number of awareness indicators that reflect their core aspects [26] (Table 1). Carroll et al. defined social awareness as people's understanding of the current social context. The co-presence of users in tabletop collaboration affects the communication as well as recognition of communication between people. In the context of our experiment, we identify verbal response as the most indicative of social awareness more so than gaze, gesture and other social interaction. Verbal response implies the realization of the social presence of others, which may lead to ad-hoc communications as a part of grounding process [20]. No or few verbal responses in the co-located context suggests that participants are less ready to give feedback, or perhaps even a failure to realize a partner's decisions [49]. A second social awareness indicator, category change, is more indirect but interpretive, tying to the core activity of categorizing cards as required by this experiment. Awareness of social presence influences collaborator feelings about the card category. Understanding to the social context of the face-to-face collaboration indicates high social awareness, but may also discourage activities of individuals, such as expressing the intent to change the card sorted by another [11].

Action awareness refers to immediate reactions to others' actions on the shared objects categorized by a collaborator. In co-located collaboration, the moment-tomoment awareness of others' actions influences one's own decisions. Too much information about actions may tax users' ability to comprehend and excessively interrupt one's own activities. Touch reaction and touch distance were used as indicators of action awareness. Gestural behaviors on touch-enabled items reflect collaborators' cognitive flow $[51,58]$. The immediate touch response to other's sorting actions indicates the perception of other's activities. Increased awareness of actions performed in the collaborative space enables participants to more easily identify changed items and understand how they influence their own tasks [22]. Touch distance is used to evaluate interruption and distraction. We describe it as the accumulated spatial distance between every adjacent touch movement. Higher touch distance implies that the collaborator shifts attentional focus from one region to another. It might interrupt deliberation on the current card and break down card exploration.

Activity awareness influences the level of coordination in collaborative task. Higher activity awareness suggests that users accurately perceive others' goals and actions, and therefore adjust their own activities for higher teamwork effectiveness. Collaborators with higher activity awareness coordinate their own actions in accordance with the others' actions, not only lending more effort to unfinished tasks but also avoiding duplicated work. In this study, we examine activity awareness as it is reflected in item 
utility and number of times a collaborator sorts previously sorted cards to the same category (called redundant sort). Number of times the collaborator moves the cards reflects overall utility of the MUMT interaction space. With increased awareness of others' activities, we assume collaborators have less concern about interaction conflicts; therefore more efforts can be spent on exploring the unused items [45]. Duplicating the sorting actions reflects people's knowledge about overall task progress. With low awareness of other's activities, a collaborator may not realize a card has been sorted and may perform a redundant action. Extraneous sorting behavior increases task burden and suggests low activity awareness, reducing task effectiveness.

Table 1. Indicators of awareness

\begin{tabular}{|c|c|c|c|}
\hline & Factor & Description & Examples \\
\hline \multirow{2}{*}{$\begin{array}{c}\text { Social } \\
\text { Awareness }\end{array}$} & $\begin{array}{c}\text { Verbal } \\
\text { Response }\end{array}$ & $\begin{array}{l}\text { Collaborator gives feed- } \\
\text { back after seeing partner's } \\
\text { activity }\end{array}$ & $\begin{array}{l}\text { Acknowledgement of changes; Indicating awareness of } \\
\text { other's presence and involvement; Verbal responses that } \\
\text { initiate ad-hoc conversations and establish common ground }\end{array}$ \\
\hline & $\begin{array}{l}\text { Category } \\
\text { Change }\end{array}$ & $\begin{array}{l}\text { Number of times a collab- } \\
\text { orator sorts previously } \\
\text { sorted cards }\end{array}$ & $\begin{array}{l}\text { Modifying others' sorting results; Reflecting level of } \\
\text { concerns on other's past decisions; Category changes that } \\
\text { indicate lower awareness of the authorship of actions or } \\
\text { fewer concerns on changing other's decisions }\end{array}$ \\
\hline \multirow{2}{*}{$\begin{array}{c}\text { Action } \\
\text { Awareness }\end{array}$} & $\begin{array}{c}\text { Touch } \\
\text { Reaction }\end{array}$ & $\begin{array}{l}\text { Collaborator identifies } \\
\text { sorted card location and } \\
\text { moves it to category }\end{array}$ & $\begin{array}{l}\text { Reacting to or showing comprehension of other's actions } \\
\text { through one's own actions; Touch reactions that influence } \\
\text { one's own future actions on the shared items }\end{array}$ \\
\hline & $\begin{array}{c}\text { Touch } \\
\text { Distance }\end{array}$ & $\begin{array}{l}\text { Accumulated distance } \\
\text { between touch actions }\end{array}$ & $\begin{array}{l}\text { Interruptions by the collaborator; Making effort to respond } \\
\text { to other's actions; Increased hand move on the tabletop }\end{array}$ \\
\hline \multirow[b]{2}{*}{$\begin{array}{c}\text { Activity } \\
\text { Awareness }\end{array}$} & Item Utility & $\begin{array}{l}\text { Number of card move- } \\
\text { ments per minute. }\end{array}$ & $\begin{array}{l}\text { Frequency of accessing different items; Stating or } \\
\text { otherwise indicating knowledge of the item category }\end{array}$ \\
\hline & $\begin{array}{l}\text { Redundant } \\
\text { Sort }\end{array}$ & $\begin{array}{l}\text { Number of times collabo- } \\
\text { rator sorts previously } \\
\quad \text { sorted cards }\end{array}$ & $\begin{array}{l}\text { Statements reflecting lack of knowledge of other's repeated } \\
\text { actions and implied intentions; Overlap in activities with } \\
\text { collaborator }\end{array}$ \\
\hline
\end{tabular}

\section{$7 \quad$ Laboratory Study}

Study participants were recruited from a community and university participant pool at our institution. During the experiment, a 55-inch Microsoft Perceptive Pixel Display tabletop is placed in the center of a laboratory room with the participants standing on opposite sides (Figure 2).

\subsection{Research Setup}

Each participant was assigned to an experiment group: the notification group or the control group. The notification group performed the card sorting task with notifications (see Figure 2). The control group worked on a system without notificationscard-sorting actions were not reflected in the partner's cards. The task asks partici- 
pants to sort up to 36 different travel destinations into 3 different categories representing 3 levels of visiting priorities: definitely visit, probably visit, possibly visit. The destinations are presented on 36 digital cards. Each card represents a well-known U.S. city (e.g., Boston, New York) with suggested days of travel and projected cost.
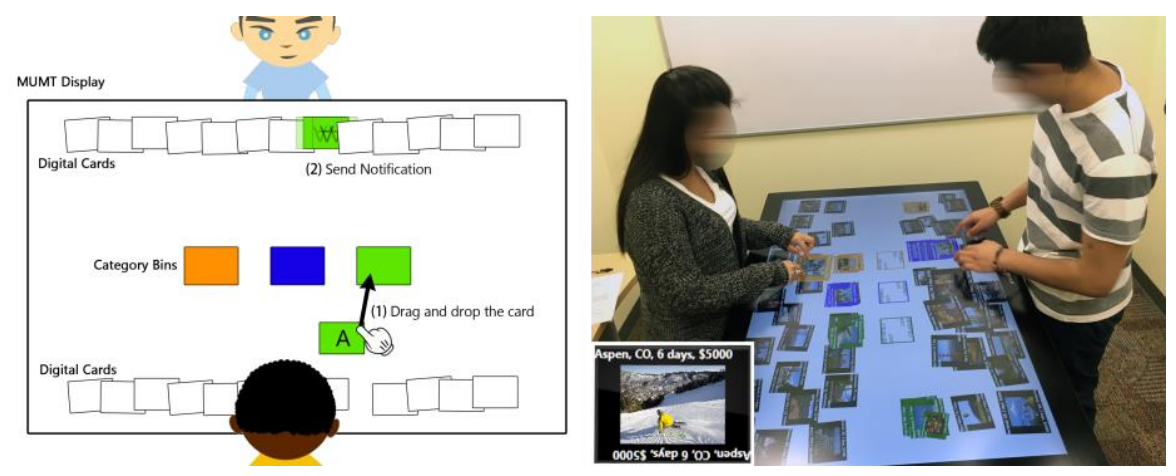

Fig. 2. Left: Interface and a notification in the card-sorting tool. Collaborators stand on two sides of the table and sort cards by dragging and dropping into category bins. Right: The experiment setup and an example card (inset).

The participants were asked to sort the cards collaboratively with their partner, evaluating destinations as a team. To categorize a card, a participant drags and drops the card to a color-coded category bin. Each card can only be in one category. Once a card is sorted, the matching card on the partner's side reflects the new category. To measure the category change, the participants were notified that after the partner sorted a card and it is not necessary to sort it sorted again if there is agreement with the card category. For the notification group, sorting results in a highlighting notification on the same card on the partner's side and changes its background color. For the control group, sorting a card has no visual effect on the partner's card.

Participants were informed of the task requirements and system use and practiced with the system by moving and sorting an unrelated set of cards. The participants were told to sort around 15 cards based on the provided information on the card. They were also instructed that each category should contain at least 1 card, the task terminates if lasts longer than 20 minutes and one should not use the card on the partner's side. 61 participants (60 undergraduate and 1 graduate student, 37 females, mean age 19.9, SD 1.5) took part in the experiment. The participants had various majors: computer science ( $\mathrm{N}=9$ ), psychology (8), biology (5) and neuroscience (4). 30 participants (19 females) were in the notification group and 31 (18 females) in the control group.

\subsection{Experiment Confederate}

Variables related to personality, aggressiveness, and preferences can greatly influence study results [32]. Because we were interested in comparing reactions to partner actions and system notifications, we chose to incorporate a research confederate. A confederate is a member of the experiment team who pretends to be a participant but 
who follows a pre-defined script. The confederate was instructed to perform identical actions for all participants. The confederate's script was developed with the following criteria to measure awareness factors: (1) For both groups, the confederate sorts the equal and reasonable number of cards (Verbal and Touch Response). (2) The participants' touch actions should not be greatly interfered by the partner (Item Utility and Touch Distance). (3) The partner sorted each designated card to the same category so that the two groups have the same situation to make changes (Category Change). The variable-controlled study influences the observation of the awareness indicators in two ways. First, since the confederate performs identical sorts for all participants, each participant receives same number of notifications, therefore the participants have equal chance to give verbal responses and touch reactions to the partner, with equal likelihood of interruption by sorting actions. This helps avoid cases of low notification count. Secondly, personal preference influences choices; use of a confederate ensures the two groups experience similar conditions. This helps avoid situations of participant reluctance to change category because the partner dominates collaboration.

Table 2. Confederate script. Column 1: time for each sort. Columns $2 \& 3$ : card destination and category for each time. Column 4: whether confederate gives verbal explanation.

\begin{tabular}{|c|c|c|c|}
\hline Time(MM:SS) & Card & Category & Verbal Description \\
\hline $01: 00$ & Boston & Definitely Visit & Yes \\
\hline $01: 30$ & Annapolis & Probably Visit & No \\
\hline $02: 00$ & Washington & Possibly Visit & No \\
\hline $03: 00$ & Charleston & Definitely Visit & Yes \\
\hline $03: 30$ & Miami Beach & Probably Visit & Yes \\
\hline $04: 00$ & Napa Valley & Possibly Visit & No \\
\hline $04: 30$ & New Orleans & Definitely Visit & Yes \\
\hline $05: 00$ & Myrtle Beach & Probably Visit & No \\
\hline $05: 30$ & Richmond & Possibly Visit & No \\
\hline $06: 00$ & San Francisco & Definitely Visit & Yes \\
\hline $06: 30$ & San Antonio & Probably Visit & Possibly Visit \\
\hline $07: 00$ & Raleigh & & \\
\hline
\end{tabular}

An undergraduate research team member served as confederate and performed the card-sorting task with all participants. Participants did not know they would be working with a confederate before the study. If the participant asked questions or made a comment, the confederate gave brief feedback, but she did not engage directly with the participant's sorting activity. For example, if the participant asked "Do you want go to Boston?" The confederate will reply, "Yeah, you can sort it to whatever category you like." Before the actual experiment, the confederate practiced the task for 4 times with different persons for timing and quality.

To examine the awareness indicators under the same condition, the confederate followed the same pre-defined script across all sessions. A timer is provided at the corner of experiment room to let the confederate monitor the time. At the beginning of the task, the confederate suggests that they look at all the cards. Then after a period of time the confederate sorts one card to one category. The confederate sorts 12 cards in 
total. The order of the card sorting and categories where the cards were sorted were same with all participants, as showed in Table 2 . When sorting 6 of the 12 cards, the confederate gives a verbal explanation. When sorting the other 6 cards, the confederate does not say anything (see column 4 in Table 2). If the confederate's sorting action conflicts with the participant's ongoing speech or actions, the confederate will delay her action a few seconds to let the participant finish. Since the confederate always sorts the same set of cards with the approximately same time interval, participants' verbal and gestural reactions to the confederate's sorting actions can be compared between groups.

\subsection{Data Collecting Method}

To quantify the awareness indicators in the study, we use 2 sources of data. An overhead camera over the center of the tabletop captured and saved all actions. The system also tracked and logged each touch movement performed on the MUMT display. Card movement records start at a touch on the cards and end when all fingers on that card leave the display, with collected attributes of each record including the card content, owner, current category, start and end point timestamps and pixel coordination, and whether the card is dragged and dropped into a bin and the category of the bin.

Video Data Analysis. The verbal response for the social awareness is reflected in reactions to confederate card sorting. We focus the video analysis of card-sorting events. 5 research team members independently transcribed card-sorting events in the video records. 12 events were identified in the video track first, then the research members took records of participant verbal feedback. 2 team members transcribed the notification group and another 2 transcribed the control group, while the lead researcher transcribed all videos in both groups. Each person worked individually without interaction. Thus, each record has 3 transcription records from 3 different team members. To ensure reasonable agreement, for each card-sorting event the participant is considered to give a verbal response if at least 2 records indicate an interaction.

Touch Data Analysis. The other 5 awareness indicators were quantified from touch logs. Each card movement performed by the participants were categorized into one of 3 touch categories - moving touch (MT), sorting touch (ST) and awareness touch (AT). MTs are the card movement before the card is sorted. STs are the actions of dragging-and-dropping the card into a category bin. ATs are the touch actions of moving the cards that already be sorted. Touch reaction is measured as the number of events for which the confederate sorted a card and the participant moved that card within 10 seconds. Item utility is the number of touch movements performed by the participant, measured in touches per minute. The item utilities of the 3 touch types were measured separately. The card touching frequencies in each of the 12 cardsorting events intervals were calculated (from the beginning to the 1 st card-sorting, and all 11 intervals between the 12 card-sorting events). Touch distance is calculated as the total distance between the start points of every pair of adjacent touch movements within the 10 seconds. 12 touch distance records are recorded for each of confederate card-sorting event. Category changes and redundant sort are the card-sorting 
events in which a participant sorts a card that has already been sorted, when the card is dragged-and-dropped into the different and the same category, respectively.

\section{$8 \quad$ Results}

One participant in the control group who did not work collaboratively as instructed and whose data was not considered in the analysis. Average task time for the notification group and the control group are $8.72(\mathrm{SD}=9.55)$ and $9.55(\mathrm{SD}=2.49)$ minutes, respectively. The participants in the notification group sorted 18.00 cards on average $(\mathrm{SD}=7.64)$ and the control group sorted 18.83 cards on average $(\mathrm{SD}=8.63)$. Since the two groups do not differ in task involvement, we focused on how notification affects the social, action and activity awareness. Differences for ANOVA tests for each of the awareness indicators is considered significant at a $\mathrm{p}<0.05$ level.

\subsection{Verbal Response and Touch Reaction}

Verbal response indicates participants' social awareness of giving feedback to the confederate and touch reaction indicates the action awareness of confederate's actions. These two awareness factors both measure immediate reactions to confederate's actions. The verbal response and touch reaction form 4 conditions: (A) the participant does not have any response behavior. (B) The participant gives a verbal response, but does not touch the sorted card. (C) The participant does not give a verbal response, but has an action to move the sorted card to a storage place. (D) The participant touches the sorted card and gives verbal response. Figure 3 shows the average numbers and standard deviations (in parentheses) of events in each condition.
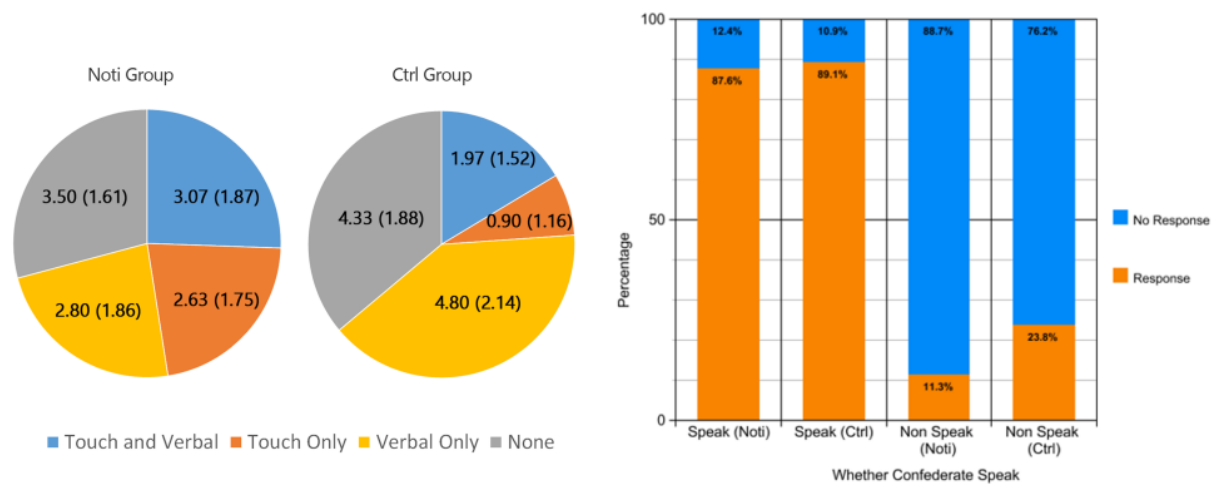

Fig. 3. Left: Numbers of confederate card-sorting events in 4 feedback conditions. Right: The 2 bars on left show percentage of events when the participant gives a verbal utterance in response to confederate verbal reasoning upon sorting. The 2 bars on the right show the percentages when the confederate sorts the card without saying anything.

When neither giving a verbal response to the confederate nor touching the card that was just sorted (condition A), the participant is less likely to notice nor is care about 
the confederate sorting behavior. In contrast, responding to the confederate's behavior and having some touch reactions (condition D) suggests that the participant paid attention to the confederate and acknowledges the idea or intent. In the study the notification group gives no response and both responses 3.5 times and 3.07 times respectively, compared to 4.33 and 1.97 for the control group in these conditions. The notification group responds significantly more times with both responses $(\mathrm{p}=0.0078)$ and fewer times giving no response ( $\mathrm{p}=0.0354)$. The results suggest that the noti group has higher awareness of confederate's sorting behaviors than the control group.

Participants in the control group make a verbal utterance an average of 4.8 times, higher than the notification group's 2.8 times $(\mathrm{p}=0.0001)$. The control group touches a card sorted by the confederate 0.9 times without a verbal reply, less than the notification group's 2.63 times $(p<0.0001)$. Considering events with both touch and verbal response, the notification group gave a verbal response 5.87 times and a touch reaction 5.7 times, compared to 6.77 and 2.87 times for the control group. The difference in condition (B) and (C) for the two groups suggests that the notification group was more likely to respond by moving a card rather than speaking to the confederate.

We further examined verbal communication based on when the confederate sorts a card. Figure 3 illustrates events when the confederate speaking resulting in participant verbal response. When the confederate said something while sorting the card, verbal replies were given almost $90 \%$ of the time regardless of group (two left bars in Figure $3)$. The notification group gives fewer verbal responses (11.3\%) when the confederate did not say anything, while the control group speaks to the confederate in $23.8 \%$ of the confederate's card-sorting events, a significant difference $(\mathrm{p}=0.0146)$ (see Figure 3 , two right bars). This indicates that the notification group is less likely to initiate a conversation after capturing confederate's action. Comparing differences in immediate reactions between the two groups, the notification group has higher action awareness than the control group, but lower social awareness in giving verbal feedback.

\subsection{Item Utility and Touch Distance}

Item utility reflects activity awareness, influencing action performance. Touch distance reflects the effort participants spent in reacting to confederate's actions. Both indicators relate to action flow during sorting. Figure 4 shows average item utilities between confederate's card-sorting events. The two groups move cards at similar frequency until the confederate sorted the third card, when the control group moves unsorted cards at a lower frequency. The average moving frequency for the notification group is $19.72(\mathrm{SD}=6.23)$ and control group is $16.14(\mathrm{SD}=6.92)$, with former significant higher than latter $(\mathrm{p}=0.0218)$. It implies that participants without notification were less effective in visiting unsorted cards, suggesting low activity awareness.

Figure 5 shows average touch distance 10 seconds before and after each of the 12 confederate's card-sorting events, with notification group (52.31 in., SD=3.20) larger than control group (41.28 in., $\mathrm{SD}=3.20, \mathrm{p}=0.0188$ ), suggesting that participants in the notification group have higher action awareness and are more likely to shift focus. After a notification, participants stop exploring the current area to focus on the highlighted card, and then resume work near the highlighted card. The cognitive break- 
down resulting from high action awareness may interrupt ongoing thoughts and ideation.

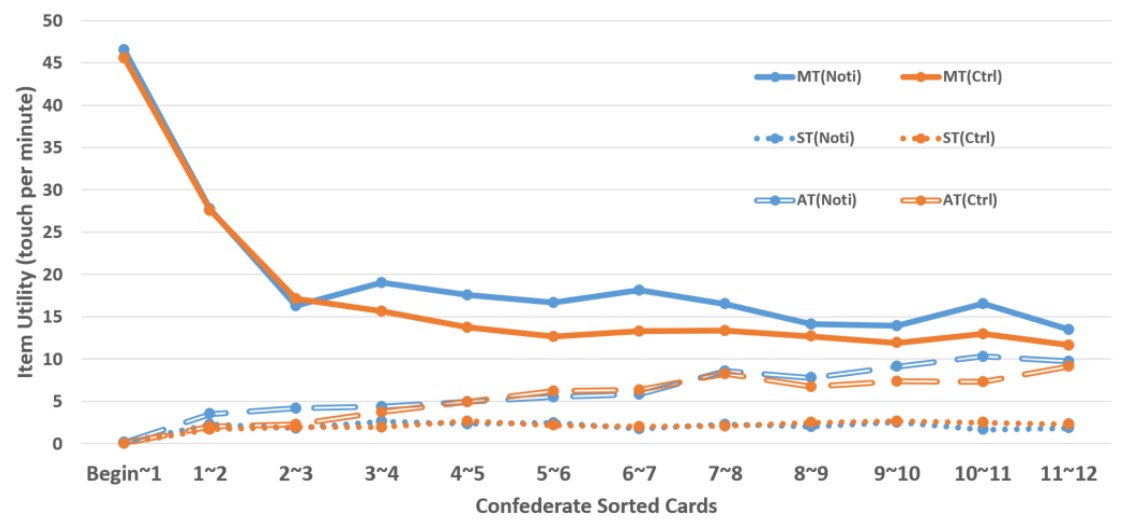

Fig. 4. Item utility of each touch type between the confederate card-sorting events.

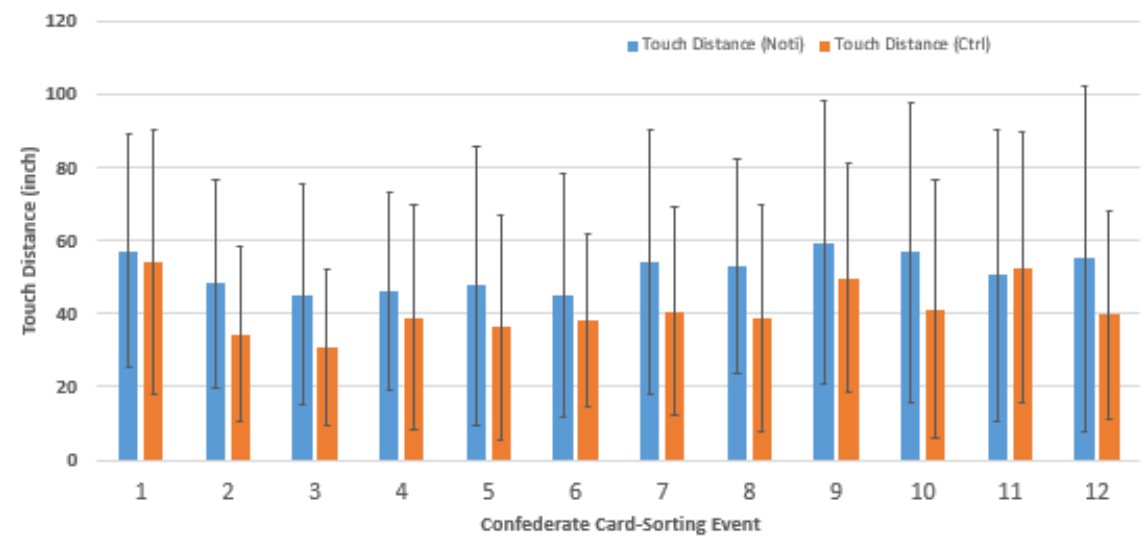

Fig. 5. The touch distances 10 seconds before and after each confederate card-sorting event. The distance is measured in inches. The error bars show \pm 1 standard deviation.

\subsection{Category Change and Redundant Sort}

Changing a card's category that was previously sorted by the confederate reflects either disagreement or lack of awareness, while unnecessarily sorting to the same category reflects low awareness. Figure 6 illustrates all category change and redundant sort instances. Only 4 participants in the notification group re-sorted cards after the confederate sorted them, with only 2 changing the category. In contrast, the control group has many more instances of re-sorting: 19 participants in the control group re-sorted at least one card to the same category, and 9 participants changed at least one card to another category. The notification group had higher awareness but also performed fewer category changes. 


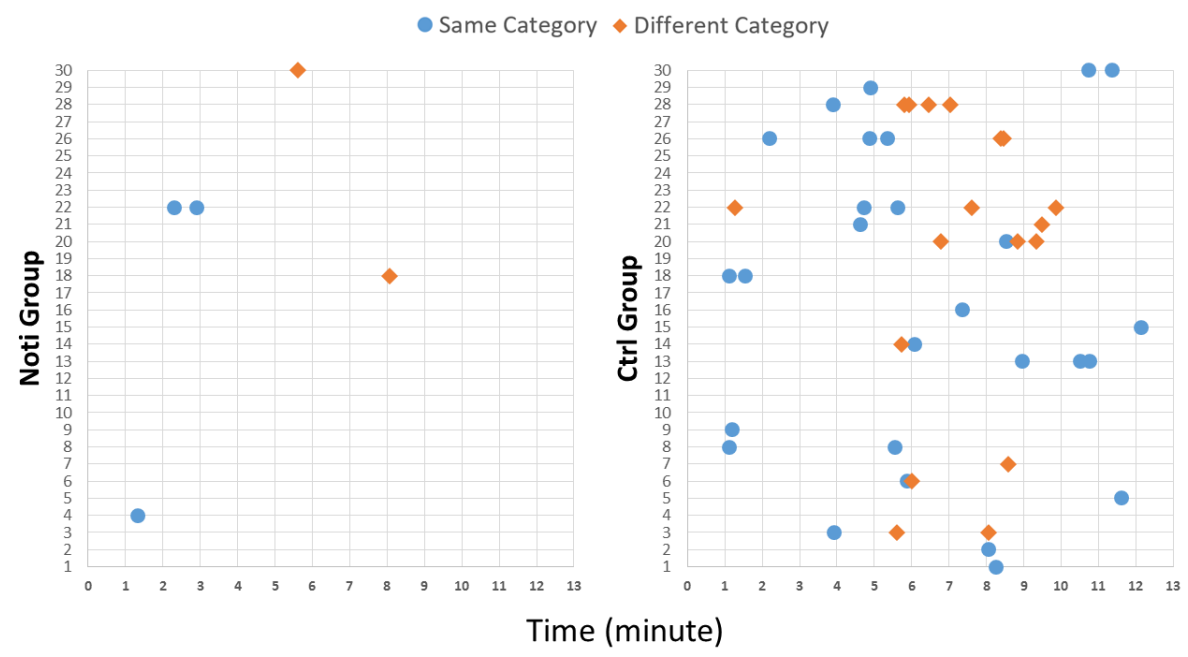

Fig. 6. Category change and redundant sort for notification (Noti) and control (Ctrl) groups.

\section{Discussion}

This study extends Carroll's model to examine how MUMT notifications affect individual work, social norms, and team performance for social, action, and activity awareness [4]. Examining our results through the lens of key concerns of the research community, this section explores these research concerns to further the understanding of the benefits and costs in using notifications.

\subsection{Influencing Individual Work}

Awareness of others' behaviors affects decisions about work [11,36]. In activities like collaborative card sorting, workers may need to clarify decisions and express opinions. Our study shows how notifications can redirect individual work by affecting item utility, expressing disagreement, and causing interruptions. Notifications deliver awareness information into the personal space, resulting in others' actions exerting influence on individual work. In co-located teamwork, perceiving and understanding others' behaviors is indispensable to individual work [53]. Historically, this occurs through observation and conversation, but notifications provide an alternate awareness path. Our study reveals how connecting with others is important in raising awareness, drawing attention to others and their personal space [54]. With notifications, it is possible to recognize others' actions within one's own interaction space. Closer indicators of other's behaviors blend with items in the individual space, affecting individual task performance. Notifications influence how awareness information is delivered, necessitating decisions on how to craft notifications to encourage behavior. The attention-attracting nature of notifications encourages mental shifts-risking workflow breakdowns by redirecting attention and action. 
When using notifications on tabletop displays, designers can employ notifications to complement collaborative awareness and intensify mutual influence between individual work, especially when collaborators engage in the personal space and risk awareness problems (e.g. opposite orientation [33] and long referring distance [9]). Users are likely to classify the items and tasks as "completed-by-others" and "to-befinished", therefore lean more considerations and actions on the latter. Benefits include more attention on the unfinished work and better item utility, but it could weaken consideration of alternatives and interrupts personal work. Designers need to consider appropriate ways to present notifications, realizing the tradeoff between intrusiveness to the individual's on-going task and increased understanding to alternatives and new possibilities brought by others' actions.

\subsection{Influencing Social Norms}

Social norms play an important role in managing co-located work for MUMTs [1, 35]. In face-to-face design activities like card sorting, participants follow social conventions and protocols to communicate and conduct joint activities. Collaborators using tabletops become aware of others' actions in two ways: by observing another person perform an action and by observing the results of the action. Our results suggest that notifications heighten awareness of partner actions, changing participant behavior - though without discussion or comment as is the norm. Instead, reactions are directed toward the shared screen via lightweight touches. Even though the instigator of an action is present, people focus on technology rather than the collaborator.

This social norm finding furthers knowledge of grounding in co-located collaboration [7, 41]. Notifications can result in reluctance to express contrary thought: since they manifest others' activities, they may increase negotiation and persuasion costs. Contrary to the notion that face-to-face communication is considered a low-cost way to build common ground [41], understanding others through notifications may supersede a need to communicate - regardless of whether it leads to optimal outcome.

Notifications facilitate development of common ground, informing collaborators of others' activities. However, the ability to react by touch rather than verbally can result in an inability to gain confirmation [41], lessening connection found in verbal responses. When employing notifications, MUMT designers must consider the effects on face-to-face communication. In applications where collaborators benefit from verbal communication, our work suggests that notifications may create negative norms that discourage collaborators from talking about key issues. Designers should leverage notifications to incite desired verbal communication while realizing the costs of the notifications: users working in parallel with notification-supported communication can increase efficiency of the collaborative task exchanges, but notifications may cause degradation in performance toward individual task goals.

\subsection{Influencing Team Performance}

In face-to-face collaboration, perceiving and processing verbal and touch actions in co-located space is time-consuming. With notifications, participants have a path to 
recognize collaborators' thoughts and intentions, lessening perceived need to discuss the action. This can decrease time communicating with partners, smoothing the move to the next action and avoiding performing extra work. Our notifications seemed to reduce this need - though we acknowledge that other types of notifications might encourage verbal communication [43].

Salas et al. identify effects between individual and team situation awareness [53]. Awareness depends on environmental elements and collaborator communication [12, 53]. In MUMT-supported collaboration, these activities might be depressed by larger interaction space [61]. Notifications add flexibility to awareness management of colocated interaction. Instead of relying on body cues and conversation, well-designed notifications can tailor visibility and availability of information, providing more freedom to users in identifying others' activities. Flexibility in awareness management smooths simultaneous interaction by reducing conflicting actions (e.g. sorting a card to different category) so collaborators can work independently without intrusion [59].

Managing concurrent activities in co-located space influences participation and mutual awareness of collaboration [10, 15, 26]. In simultaneous interactions with MUMTs, availability of multi-touch interactions mean collaborators withdraw from interpersonal interactions and avoid conflicts by engaging in individual interactionswith the danger of reducing performance and awareness. Though interpersonal communication has long been recognized as the core to building common ground, notification-based understanding may provide enough grounding information in MUMT collaboration. Tabletop designers could utilize notifications to improve collaborators' ability to work independently, especially for collaborative tasks that are suitable for divide-and-conquer, therefore improving team efficiency through simultaneous and synchronized work.

\section{Conclusions and Future Work}

Notifications have been widely employed in supporting collaboration - they deliver current and important events in the collaborative space and heighten the awareness of other activities [4,39]. Prior work on awareness-enhancing designs and tools on MUMTs focus on supporting the awareness for a single workspace element. This study expands previous knowledge by providing a critical understanding of using notifications in MUMT-supported collaboration. Three types of awareness are evaluated through a user study: social awareness, action awareness, and activity awareness. Our findings are grounded in contextual differences between traditional computersupported collaboration and the action-highlighting collaboration on a shared tabletop display. Benefits and costs of using notifications are presented to foster future notification design for MUMT-based groupware.

Future work will investigate notification effect on personal and shared spaces in MUMTs. This research considered limited situations; it is important to consider approaches in which the style, number, and level of interaction differ. Also, notifications in this study affect interactions in limited ways, and it would be helpful to identify ways that notifications encourage and facilitate positive interpersonal communication. 


\section{References}

1. Al-Qaraghuli, A., Zaman, H.B., Olivier, P., Kharrufa, A., Ahmad, A.: Analysing tabletop based computer supported collaborative learning data through visualization. In: Visual Informatics: Sustaining Research and Innovations: Second International Visual Informatics Conference, IVIC 2011. pp. 329-340 Springer, Berlin, Heidelberg, Berlin, Heidelberg (2011).

2. Bartram, L., Ware, C., Calvert, T.: Moticons:: detection, distraction and task. Int. J. Hum. Comput. Stud. 58, 5, 515-545 (2003).

3. Bortolaso, C., Oskamp, M., Phillips, W.G., Gutwin, C., Graham, T.C.N.: The Effect of View Techniques on Collaboration and Awareness in Tabletop Map-Based Tasks. BT Proceedings of the Ninth ACM International Conference on Interactive Tabletops and Surfaces, ITS 2014, Dresden, Germany, November 16 - 19, 2014. (2014).

4. Carroll, J.M., Neale, D.C., Isenhour, P.L., Rosson, M.B., McCrickard, D.S.S.: Notification and awareness: synchronizing task-oriented collaborative activity. Int. J. Hum. Comput. Stud. 58, 5, 605-632 (2003).

5. Charleer, S., Klerkx, J., Odriozola, S., Luis, J., Duval, E., Santos Odriozola, J.L., Duval, E.: Improving awareness and reflection through collaborative, interactive visualizations of badges. In: ARTEL13: Proceedings of the 3rd Workshop on Awareness and Reflection in Technology-Enhanced Learning. pp. 69-81 CEUR-WS (2013).

6. Chewar, C.M., McCrickard, D.S., Sutcliffe, A.G.: Unpacking critical parameters for interface design. In: Proceedings of the 2004 conference on Designing interactive systems processes, practices, methods, and techniques - DIS '04. p. 279 ACM, Cambridge, MA, USA (2004).

7. Clark, H.H., Brennan, S.S.E.: Grounding in communication. In: Perspectives on socially shared cognition. pp. 127-149 (1991).

8. Van Dantzich, M., Robbins, D., Horvitz, E., Czerwinski, M.: Scope: Providing awareness of multiple notifications at a glance. In: Proceedings of the Working Conference on Advanced Visual Interfaces. pp. 267-281 ACM, Trento, Italy (2002).

9. Doucette, A., Gutwin, C., Mandryk, R.: Effects of arm embodiment on implicit coordination, co-presence, and awareness in mixed-focus distributed tabletop tasks. In: Proceedings of the 41st Graphics Interface Conference. pp. 131-138 Canadian Information Processing Society, Halifax, Nova Scotia, Canada (2015).

10. Doucette, A., Gutwin, C., Mandryk, R.L., Nacenta, M.A., Sharma, S.: Sometimes when we touch: how arm embodiments change reaching and collaboration on digital tables. In: Proceedings of the 2013 conference on Computer Supported Cooperative Work (CSCW '13). pp. 193-202 ACM, San Antonio, Texas, USA (2013).

11. Dourish, P., Bellotti, V.: Awareness and coordination in shared workspaces. In: Proceedings of the 1992 ACM conference on Computer-supported cooperative work. pp. 107-114 ACM, New York, New York, USA (1992).

12. Endsley, M.R.: Toward a Theory of Situation Awareness in Dynamic Systems. Hum. Factors J. Hum. Factors Ergon. Soc. 37, 1, 32-64 (1995).

13. Endsley, M.R., M. Robertson, M.: Situation awareness in aircraft maintenance teams. Int. J. Ind. Ergon. 26, 2, 301-325 (2000).

14. Fan, M., Antle, A.N., Neustaedter, C., Wise, A.F.: Exploring how a co-dependent tangible tool design supports collaboration in a tabletop activity. In: Proceedings of the 18th International Conference on Supporting Group Work (GROUP '14). pp. 81-90 ACM, Sanibel Island, Florida, USA (2014). 
15. Fischer, J.E., Reeves, S., Moran, S., Greenhalgh, C., Benford, S., Rennick-Egglestone, S.: Understanding Mobile Notification Management in Collocated Groups. In: Bertelsen, O.W. et al. (eds.) ECSCW 2013: Proceedings of the 13th European Conference on Computer Supported Cooperative Work. pp. 21-44 Springer, London (2013).

16. Fussell, S.R., Kraut, R.E., Lerch, F.J., Scherlis, W.L., McNally, M.M., Cadiz, J.J.: Coordination, Overload and Team Performance: Effects of Team Communication Strategies. In: Proceedings of the 1998 ACM Conference on Computer Supported Cooperative Work. pp. 275-284 ACM, New York, NY, USA (1998).

17. Fussell, S.R., Kraut, R.E., Siegel, J.: Coordination of Communication: Effects of Shared Visual Context on Collaborative Work. In: Proceedings of the 2000 ACM Conference on Computer Supported Cooperative Work. pp. 21-30 ACM, New York, NY, USA (2000).

18. Gergle, D., Kraut, R.E., Fussell, S.R.: Action As Language in a Shared Visual Space. In: Proceedings of the 2004 ACM Conference on Computer Supported Cooperative Work. pp. 487-496 ACM, New York, NY, USA (2004).

19. Gergle, D., Kraut, R.E., Fussell, S.R.: Language Efficiency and Visual Technology. J. Lang. Soc. Psychol. 23, 4, 491-517 (2004).

20. Gergle, D., Kraut, R.E., Fussell, S.R.: Using Visual Information for Grounding and Awareness in Collaborative Tasks. Human-Computer Interact. 28, 1, 1-39 (2013).

21. Di Giacomo, E., Lubiw, A., Zimmer, B., Kerren, A., Cernea, D., Weber, C., Kerren, A., Ebert, A.: Group Affective Tone Awareness and Regulation through Virtual Agents. In: IEEE Information Visualization. pp. 247-259 Springer (2014).

22. Gutwin, C., Greenberg, S.: A descriptive framework of workspace awareness for real-time groupware. Comput. Support. Coop. Work (CSCW '02). 11, 3-4, 411-446 (2002).

23. Gutwin, C., Greenberg, S.: Design for Individuals, Design for Groups: Tradeoffs Between Power and Workspace Awareness. In: Proceedings of the Conference on ComputerSupported Cooperative Work. pp. 207-216 ACM, Seattle, Washington, USA (1998).

24. Gutwin, C., Roseman, M., Greenberg, S.: A Usability Study of Awareness Widgets in a Shared Workspace Groupware System. In: Proceedings of the 1996 ACM conference on Computer supported cooperative work. pp. 258-267 ACM, New York, NY, USA (1996).

25. Hinrichs, U., Carpendale, S.: Gestures in the wild. In: Proceedings of the 2011 annual conference on Human factors in computing systems - CHI '11. p. 3023 ACM, Vancouver, BC, Canada (2011).

26. Hornecker, E., Marshall, P., Dalton, N.S., Rogers, Y.: Collaboration and interference: awareness with mice or touch input. In: Proceedings of the 2008 ACM conference on Computer supported cooperative work. pp. 167-176 ACM, New York, NY, USA (2008).

27. Hudson, W.: Card sorting. Encycl. Human-Computer Interact. 2nd Ed. (2013).

28. Ion, A., Chang, Y.-L.B., Haller, M., Hancock, M., Scott, S.D.: Canyon: providing location awareness of multiple moving objects in a detail view on large displays. In: Proceedings of the SIGCHI Conference on Human Factors in Computing Systems - CHI '13. p. 3149 ACM, Paris, France (2013).

29. Isenberg, P., Elmqvist, N., Scholtz, J., Cernea, D., Ma, K.-L., Hagen, H., Kwan-Liu Ma, K.-L., Hagen, H.: Collaborative visualization: definition, challenges, and research agenda. In: Information Visualization. pp. 310-326 SAGE PublicationsSage UK: London, England (2011).

30. Isenberg, P., Fisher, D., Paul, S.A., Morris, M.R., Inkpen, K., Czerwinski, M., Paul, S.A., Morris, M.R., Inkpen, K., Czerwinski, M.: An exploratory study of co-located collaborative visual analytics around a tabletop display. In: 2010 IEEE Symposium on Visual Analytics Science and Technology (VAST). pp. 179-186 IEEE, Salt Lake City, Utah, USA (2010). 
31. Isenberg, P., Tang, A., Carpendale, S.: An exploratory study of visual information analysis. In: Proceedings of the SIGCHI Conference on Human Factors in Computing Systems. pp. 1217-1226 ACM, Florence, Italy (2008).

32. Kohn, M.L., Schooler, C.: Work and personality: An inquiry into the impact of social stratification. Ablex Pub (1983).

33. Kruger, R., Carpendale, S., Scott, S.D., Greenberg, S.: Roles of orientation in tabletop collaboration: Comprehension, coordination and communication. Comput. Support. Coop. Work. 13, 5-6, 501-537 (2004).

34. Lee, J., Tatar, D., Harrison, S.: Micro-coordination: because we did not already learn everything we need to know about working with others in kindergarten. In: Proceedings of the ACM 2012 conference on Computer Supported Cooperative Work (CSCW '12). pp. 1135-1144 ACM, Seattle, Washington, USA (2012).

35. Mark, G., Fuchs, L., Sohlenkamp, M.: Supporting Groupware Conventions through Contextual Awareness. In: Proceedings of the Fifth European Conference on Computer Supported Cooperative Work. pp. 253-268 Springer, Dordrecht (1997).

36. Mark, G., Kobsa, A., Gonzalez, V., Clark, H.H., Brennan, S.E., Endsley, M.R., M. Robertson, M., Rittenbruch, M., Salmon, P.M., Stanton, N.A., Walker, G.H., Baber, C., Jenkins, D.P., McMaster, R., Young, M.S.: What really is going on? Review of situation awareness models for individuals and teams. Inf. Vis. 2002. Proceedings. Sixth Int. Conf. 14, 2, 127-149 (2002).

37. Marshall, P., Hornecker, E., Morris, R., Dalton, N.S., Rogers, Y.: When the fingers do the talking: A study of group participation with varying constraints to a tabletop interface. In: 3rd IEEE International Workshop on Horizontal Interactive Human Computer Systems (TABLETOP 08) . pp. 33-40 (2008).

38. McCrickard, D.S., Abel, T.D., Scarpa, A., Wang, Y., Niu, S.: Collaborative design for young children with autism: Design tools and a user study. In: 2015 International Conference on Collaboration Technologies and Systems (CTS). pp. 175-182 IEEE (2015).

39. McCrickard, D.S., Chewar, C.M.: Attuning notification design to user goals and attention costs, http://portal.acm.org/citation.cfm?doid=636772.636800, (2003).

40. McCrickard, D.S.S., Czerwinski, M., Bartram, L.: Introduction: design and evaluation of notification user interfaces. Int. J. Hum. Comput. Stud. 58, 5, 509-514 (2003).

41. Monk, A.: Common ground in electronically mediated communication: Clark's theory of language use. (2014).

42. Morris, M.R., Fisher, D., Wigdor, D.: Search on surfaces: Exploring the potential of interactive tabletops for collaborative search tasks. Inf. Process. Manag. 46, 6, 703-717 (2010).

43. Morris, M.R., Lombardo, J., Wigdor, D.: WeSearch: Supporting collaborative search and sensemaking on a tabletop display. In: Proceedings of the 2010 ACM conference on Computer Supported Cooperative Work (CSCW '10). pp. 401-410 ACM, Savannah, Georgia, USA (2010).

44. Morris, M.R., Paepcke, A., Winograd, T., Stamberger, J.: TeamTag: exploring centralized versus replicated controls for co-located tabletop groupware. In: Proceedings of the SIGCHI conference on Human Factors in computing systems. pp. 1273-1282 ACM, Montréal, Québec, Canada (2006).

45. Morris, M.R., Ryall, K., Shen, C., Forlines, C., Vernier, F.: Beyond "social protocols": multi-user coordination policies for co-located groupware, (2004).

46. Paul, C.L., Komlodi, A., Lutters, W.: Interruptive notifications in support of task management. Int. J. Hum. Comput. Stud. 79, 20-34 (2015). 
47. Peltonen, P., Kurvinen, E., Salovaara, A., Jacucci, G., Ilmonen, T., Evans, J., Oulasvirta, A., Saarikko, P.: It's Mine, Don't Touch!: interactions at a large multi-touch display in a city centre. In: Proceedings of the SIGCHI Conference on Human Factors in Computing Systems (CHI '08). pp. 1285-1294 ACM, Florence, Italy (2008).

48. Piper, A.M., O’Brien, E., Morris, M.R., Winograd, T.: SIDES: a cooperative tabletop computer game for social skills development. In: Proceedings of the 2006 ACM conference on Computer Supported Cooperative Work (CSCW '06). pp. 1-10 ACM, Banff, Alberta, Canada (2006).

49. Reeves, B., Nass, C.: How people treat computers, television, and new media like real people and places. CSLI Publications and Cambridge university press Cambridge, UK (1996).

50. Rittenbruch, M.: Atmosphere: A Framework for Contextual Awareness. Int. J. HumanComputer Interact. 14, 2, 159-180 (2002).

51. Rogers, Y., Hazlewood, W., Blevis, E., Lim, Y.-K.: Finger talk: collaborative decisionmaking using talk and fingertip interaction around a tabletop display. In: CHI '04 Extended Abstracts on Human Factors in Computing Systems (CHI EA '04). pp. 12711274 ACM, Vienna, Austria (2004).

52. Ryall, K., Forlines, C., Shen, C., Morris, M.R.: Exploring the effects of group size and table size on interactions with tabletop shared-display groupware. In: Proceedings of the 2004 ACM conference on Computer supported cooperative work - CSCW '04. p. 284 ACM, Chicago, Illinois, USA (2004).

53. Salas, E., Prince, C., Baker, D.P., Shrestha, L.: Situation Awareness in Team Performance: Implications for Measurement and Training. Hum. Factors J. Hum. Factors Ergon. Soc. 37, 1, 123-136 (1995).

54. Scott, S.D., Carpendale, M.S.T., Inkpen, K.M., Sheelagh, M., Carpendale, T., Inkpen, K.M.: Territoriality in collaborative tabletop workspaces. In: Proceedings of the 2004 ACM conference on Computer Supported Cooperative Work (CSCW '04). pp. 294-303 ACM, Chicago, Illinois, USA (2004).

55. Scott, S.D., Grant, K.D., Mandryk, R.L.: System guidelines for co-located, collaborative work on a tabletop display. In: Kuutti, K. et al. (eds.) Proceedings of the Eighth European Conference on Computer Supported Cooperative Work (ECSCW '03). pp. 159-178 Springer Netherlands, Dordrecht (2003).

56. Shuo Niu, McCrickard, D.S., Nguyen, S.M.: Learning with interactive tabletop displays. In: 2016 IEEE Frontiers in Education Conference (FIE). pp. 1-9 IEEE (2016).

57. Smith, K., Hancock, P.A.: Situation Awareness Is Adaptive, Externally Directed Consciousness. Hum. Factors J. Hum. Factors Ergon. Soc. 37, 1, 137-148 (1995).

58. Tang, A., Pahud, M., Carpendale, S., Buxton, B.: VisTACO: visualizing tabletop collaboration. In: ACM International Conference on Interactive Tabletops and Surfaces. pp. 29-38 ACM, Saarbrücken, Germany (2010).

59. Tang, A., Tory, M., Po, B., Neumann, P., Carpendale, S.: Collaborative coupling over tabletop displays. In: Proceedings of the SIGCHI Conference on Human Factors in Computing Systems (CHI '06). pp. 1181-1190 ACM, Montréal, Québec, Canada (2006).

60. Wobbrock, J.O., Morris, M.R., Wilson, A.D.: User-defined gestures for surface computing. In: Proceedings of the SIGCHI Conference on Human Factors in Computing Systems. pp. 1083-1092 ACM, Boston, MA, USA (2009).

61. Zagermann, J., Pfeil, U., Rädle, R., Jetter, H.-C., Klokmose, C., Reiterer, H.: When Tablets meet Tabletops: The Effect of Tabletop Size on Around-the-Table Collaboration with Personal Tablets. In: Proceedings of the 2016 CHI Conference on Human Factors in Computing Systems. pp. 5470-5481 ACM, Santa Clara, California, USA (2016). 